\title{
Experience with Online and Open-Web Exams
}

\author{
Edward F. Gehringer | Barry W. Peddycord III
}

As homework and other aspects of education migrate to a computer-based format, on-paper exams are beginning to seem like an anachronism. Online delivery is attractive, but comes with a myriad of implications not apparent at first glance. It affects the kinds of questions that can be asked and complicates administration of the exam, but it may make grading quicker. An online exam does not necessarily make cheating easier, though it demands new approaches to preventing cheating. An open-web exam is a special kind of online exam, in which students are allowed to use the Internet while taking the exam. It has its own set of advantages and disadvantages. For example, it provides a more authentic experience, but may make it hard to tell if students have done their own work. The authors report on a research study of online exams, based on the observations of hundreds of students and faculty who filled out two online surveys. Results will guide instructors in choosing the format that is right for their class.

Most examinations are administered in an environment that is becoming artificial. Today, ideas are routinely communicated using computers; for example to perform technical work or even write a piece of prose many use the aid of a computer. That is the situation that students are in when they take an exam on paper. Faculty have plenty of opportunities to administer tests online. Textbook publishers, as well as learning-management systems, have online modules that could be used to deliver quizzes or exams. Students can use their laptops to take an exam online, even in an ordinary classroom. But online administration raises several issues, which instructors should think through before taking the plunge.

To uncover the implications of online exams, the authors set up a research study, surveying instructors on four teaching-related listservs: the Engineering Technology listserv; SIGCSE-members (computer science faculty); the College Board's APCS list; and the listserv of the Professional \& Organization Development Network in Higher Education; and students in the first author's classes from
Fall 2009 until Spring 2011. Eighty-five instructors and 315 students responded to the survey. All of them had experience administering or taking online and/or "open-Web" exams, where students were given unfettered access to the Internet during the exam, but forbidden to communicate with others. This study investigated several aspects of online exams, classifying its observations into six categories: material covered, administration of the exam, grading, academic integrity, handwriting vs. coding, and miscellaneous.

\section{MATERIAL COVERED}

Online exams make it possible to ask more kinds of questions. An instructor might have the students run a particular simulation or animation and explain the observed results. The instructor might ask the students to peruse a set of online documents to find the inputs necessary to solve a certain problem. In a traditional hardcopy exam format this would waste paper. The instructor might forgo providing some useful documents, simply to save paper.

In many fields, exam questions can often be 
answered by drawing a diagram. Unfortunately, it is difficult to draw diagrams on traditional desktop or laptop computers. Thus, the online format precludes asking such questions unless all students have tablet computers, and the testing software is capable of handling such diagrams.

Another complication is that it may be difficult to create multipart questions. The testing software may not support multipart questions, and even if it does, it may impose restrictions that make multipart questions infeasible. In the Moodle learningmanagement system (LMS), for example, a manually graded "essay" question is only allowed to have one part. It's not possible to get around this restriction by treating the parts of the question as separate questions, because most testing systems allow the instructor to "randomize" the order of questions to inhibit cheating. After randomization, the different questions would be distributed throughout the exam.

\section{ADMINISTRATION}

If timed, online exams afford all students the same amount of time. No one gets the test paper before another; no one can try the instructor's patience by staying late. Online exams allow time-shifting: students can be allowed to begin the exam at a time of their choosing. When exams are administered outside of class, students can be given almost an unlimited amount of time. But time-shifting comes at a cost. It makes it difficult or impossible to proctor the exam, and thus enables cheating.

Online exams also allow location-shifting. Students can be permitted to take exams off site while on business travel, deployed in the military, or out of town for a family emergency. Location-shifting can also expedite misconduct. Traditionally, an instructor can abate cheating by bringing all students together in the same room, where they can be observed. It may still be possible to allow a few students to take exams out of class in exceptional cases. These students' answers can be subjected to stricter scrutiny. For example, their scores can be compared with other exams taken face-to-face by the same students.

Online exams have other drawbacks. Giving an exam to an unregistered student is much more difficult; such a student may be finishing up an incomplete in a course, or taking an exam with a different section because of schedule constraints. With a traditional paper-and-pencil exam, the student can simply be handed a test paper in class. With an online exam, the student either needs to be added to the class roster used by the testing system, or a separate exam may have to be created in the testing system, for just this student.

With an online exam, innocent mistakes can become security risks. Many an instructor has inadvertently set an exam to turn on too early, or made answers available to students before the exam ended. Such mistakes may go unnoticed for a while, especially if students are taking the exam at times of their own choosing. Exams do not look quite the same in all browsers. Text boxes may appear in different places. In the Moodle quizzing system, we found that text boxes covered up the questions on certain browsers. Early versions of Google Chrome tended to freeze up, especially when the window was scrolled horizontally. Sometimes this forced us to allow students to retake the exam.

In some networks, a connection may be closed if a student spends "too much" time working on a problem without touching the computer. One of our instructor respondents reported that a student was locked out of an unfinished exam after the connection was dropped, and ultimately needed to retake the entire exam. Some less-than-honest students have used the network as an excuse for not finishing an exam, reporting a network problem but failing to show any proof..

There are also problems related to saving work. In Moodle, when time expires, the last saved copy of a student's work is submitted, and any unsaved changes are lost. Inevitably this catches some students on their first online exam. One instructor using Blackboard reported that students who click on "Save" instead of "Submit" at the end of the exam lose their work. In some systems, such as Desire2Learn, the Save and Submit buttons are near each other, raising the danger of unintentionally terminating the exam.

\section{GRADING}

Instructors who teach large classes may be attracted to online exams because of the potential for automated grading. When it works, it is a godsend. On the downside, it tends to encourage multiple-choice questions, since they can be reliably auto graded. This may not be the best approach pedagogically, but it is not a consequence of online administration; the same tendency occurs with paper-based exams. 
Most systems can also automatically grade matching and numeric-answer questions. The time savings allows more frequent exams, which can produce learning gains (McDaniel, Roediger, \& McDermott, 2007). Moreover, feedback can be immediate, and the student is likely to pay more attention to it while the question is still in mind. In the case of final exams, online feedback benefits students who must leave town before their exams are graded. They can log in, see where they lost points, and challenge suspected grading errors.

Online systems allow questions that have text answers, which must be manually graded. Manual grading is often easier on an online exam. In a paper exam, when many students make the same mistake, instructors tire of writing identical feedback on each paper. With an online system, they can save a set of standard comments, then cut and paste them into different exams. If a wrong answer is given to a multiple-choice question, an automated system can give feedback to the student that is explicitly tailored for the specific misconception behind each incorrect response.

With online exams, no paper-shuffling is involved in manually grading questions. An instructor can finish one question on every student's exam before moving on to the next question. This makes it easy to construct and apply a mental rubric, and promotes consistent grading of essay questions. It may also save time, because the instructor does not lose context in switching from question to question.

In a large class, the exam papers do not have to be divvied up among multiple graders; several people can grade simultaneously. If someone forgets to grade a question, the instructor can point that out, and the grader in charge of that question can handle it without the need to retrieve the exam paper from whoever now has it.

Online systems automatically record grades. This prevents accidental loss of information. It also provides valuable data for assessment, especially if individual questions can be tied to learning objectives.

But there are downsides to automated grading. For single-word and fill-in-the-blank answers, it is nearly impossible to anticipate all of the spellings, punctuation, and wordings that students may give. If the answer is numeric, precision and rounding can cause problems. In some systems, an instructor cannot review grades assigned by the system, except by navigating to each student's exam, and clicking on the question number. Thus, automatic grading can sometimes take more time than manual grading. It is also more difficult to give partial credit on automatically graded questions; in fact, some systems may not allow it at all. This can negatively impact student scores.

\section{ACADEMIC INTEGRITY}

Perhaps no topic attracted as much attention from instructors as academic integrity. In many of their minds, online testing is associated with examinations that are not proctored, which offer copious opportunities for collusion. It is, of course, possible to proctor online exams, especially in classrooms at schools that require students to own laptops. Software such as SecurExam or ExamSoft can "lock down" browsers to prevent students from communicating or visiting unauthorized sites during the exam. Most exam applications can randomize the order of questions, and the order of multiple-choice answers, which makes it harder for students to copy each other's work. Numerical questions can be set to give students different input values, so that the correct answer will be different for each student. The exam can even be set up to prevent students from revisiting earlier questions, though many students find that frustrating.

\section{HANDWRITING VS. CODING}

Handwriting is a handicap for both students and instructors. Most students can type faster than they can write, and the ability to edit, spell-check, and grammar-check what they have written helps them produce better prose. They can spend more time thinking, and less time writing. Faculty do not lose time trying to decipher student handwriting.

Offsetting these advantages is the need to code questions for the testing software. Fill-in-the-blank and short-answer questions are hard to code, because of the difficulty of anticipating all correct responses. Multiple-choice is easy to code, but it is time-consuming to devise distractor responses that mimic student misconceptions. If a question requires complicated formatting or involves filling in blanks in a table, it generally cannot be created with a WYSIWYG editor in the testing application. It is necessary to use an external application, such as Dreamweaver or Microsoft Expression Web Designer, but these do not support the commands 
needed for automatic grading. A teacher must go back and forth between the applications, usually several times, to eliminate all formatting glitches.

Beyond that, the testing system may treat certain characters as control codes. For example, the Moodle quizzing system treats a " $<$ " as the beginning of an HTML tag, even when it appears in an answer blank. When it saves the answer, it drops everything between the "<" and the "matching" ">", which can cause equations and programming-language statements to be completely discarded.

Mathematical questions require a specialized form of data entry, such as an equation editor. Students and instructors are rarely accustomed to these, and may find them hard to use. Moreover, students, who on a paper exam might show their work, are reluctant to type each step into an equation editor. So there is less information to use in awarding partial credit.

\section{MISCELLANEOUS}

Online exams may increase privacy, since students do not have a chance to see others' scores when papers are returned in class. Online exams save paper, which is not only eco-friendly, but also a boon to tight supply budgets. It is convenient for an instructor to reuse questions that have been used in an earlier online exam, but be aware that there are Web sites like Course Hero that collect previous exams and solutions from students. This is critical if students will have Web access during the exam.

Unfortunately, it is harder for students to scan through an online exam before starting work on it. Accessibility may be an issue for the visually impaired, especially if the exam uses material outside the testing system, such as animations. Finally, if an instructor has several years' worth of questions stored in a particular online application, and the institution switches to a different system, it may be very time consuming and difficult to convert the questions.

\section{ISSUES SPECIFIC TO OPEN-WEB EXAMS}

An exam may be administered on a computer, or on paper. Students may or may not be allowed to browse the Web. The two issues are independent; one can give an open-Web exam where students write their answers on a test paper. Open-Web onpaper exams bypass all of the technological hurdles enumerated in previous sections.
Whether delivered by computer or not, openWeb exams have their peculiar advantages and disadvantages. Because the environment resembles the setting in which students and others perform their daily work, the exam can be a more authentic assessment (Wiggins, 1990) of what the students know. Questions can be posed that require the students to search for and apply information. Recall questions, however, cannot be asked. Even explanations can be looked up, so if students are asked to tell why a particular phenomenon occurs, instructors should check that they have not simply cut and pasted their answer. Even if they have not copied an answer, they may have reworded one. One needs to frame questions carefully in order to judge whether students really do understand the concept.

After their first open-Web exam, several students volunteered their opinion that they would have done better had they not spent so much time looking up information on the Web. This is consistent with the observations of Boniface (1985) and Ioannidou (1997), as quoted by Rakes (2008), who found that some students performed more poorly on open-book than on closed-book tests, because they spent time looking through their textbook or notes. On subsequent exams, the author warned students to spend less time browsing and more time answering the questions.

Open-Web exams close certain avenues for cheating while opening others. In most open-Web exams, it is reasonable to allow the students also to consult print resources during the exam. This removes the need to monitor what the students are reading during the exam. Unauthorized communication is another matter. There is no technological way to prevent students from consulting others during the exam. Even if all known e-mail, instant message (IM), and other communication programs were blocked, students could write their own chat server and run it on a Web site during the exam. Locking down the browser simply defeats the purpose of an open-Web exam.

Thus, vigilance is necessary on the part of the proctors. Fortunately, this is not as difficult as it might seem. A proctor who sits in the back row of a theater-style classroom can easily see twenty to thirty laptop screens at one time. It is more difficult in a classroom with a level floor, but these classrooms typically hold far fewer students. Being behind the students is a deterrence, because a student 
Table 1: Results of the student survey on online and open-Web exams

\begin{tabular}{|c|ccc|}
\hline \multicolumn{2}{|c}{ All students } & Open-Web online & Open-Web on paper \\
\hline $\begin{array}{c}\text { Number questions were } \\
\text { relevant to the material } \\
\text { covered in class. }\end{array}$ & 315 & 234 & 3.37 \\
\hline $\begin{array}{c}\text { The test format of open- } \\
\text { book, open-web was beneficial. }\end{array}$ & 4.89 & 4.31 & 4.25 \\
\hline $\begin{array}{c}\text { The format was relevant } \\
\text { to the way work is done in } \\
\text { business/profession. }\end{array}$ & 3.72 & 3.87 & 3.30 \\
\hline $\begin{array}{c}\text { Taking the test online (or } \\
\text { open-Web) worked well }\end{array}$ & 3.58 & 3.53 & 3.73 \\
\hline $\begin{array}{c}\text { The exam structure } \\
\text { allowed students to cheat. }\end{array}$ & 1.91 & 1.91 & 1.93 \\
\hline
\end{tabular}

Note: Students were quite positive on the format of the exam, especially on the ability to use the Web. The classes that wrote their answers on paper thought the format worked slightly better than the classes that took the exam online. This may reflect the difficulty that students in the latter group had with the software (e.g., losing unsaved work and having some answers truncated).

can never know whom the proctor is watching.

In the first published study on open-Web exams, Williams and Wong (2007) found that students were only slightly more likely to believe that the exam structure allowed students to cheat $(2.83$ for open-Web exams, vs. 2.63 for closed-book exams on a Likert scale of 1 to 5 , with 5 meaning cheating was easy, $\mathrm{n}=54$ ). Their exams, however, were taken at different locations and times. In our classes, students were required to take the exam in designated rooms at designated times. Our student respondents $(n=315)$ gave an average score of only 1.91 to the question of whether students were able to cheat. Table 1 reports the results of our student survey. Gehringer (2010) goes into more detail on the 2009 results.

\section{THE BIG PICTURE: RECAPPING OUR FINDINGS}

Table 2 summarizes the advantages and disadvantages of online and open-Web formats. We may observe that the inherent disadvantages of online and open-Web formats are largely related to academic integrity. Even the two inherent "administrative" disadvantages relate to the difficulty of detecting cheating. Over time, then, we may expect most categories of disadvantages to disappear. The decision of whether to test online will then depend heavily on what kinds of cheating the instructor wishes to preclude.

The author's students were quite positive on the open-Web format. To the question, "The test format of open-book, open-Web was beneficial," they gave a rating of 4.29 (on a scale of 5). On the question, "Taking the test as an open-Web exam worked well," the students who used the paper-based exam rated it slightly better $(3.73, n=81)$ than the students who took their exam online $(3.53, n=234)$. This may reflect the difficulties that some students had with the online-exam software.

Open-Web exams have a particular advantage in situations where students need to look up large amounts of material during the exam. Online exams 


\section{Table 2: Advantages and Disadvantages of Online and Open-Web Exams}

Disadvantages may be either technological (-) or inherent $(x)$

\section{COVERAGE}

\begin{tabular}{|c|c|}
\hline+ & Can ask questions that require a lot of background material \\
\hline- & Cannot ask questions that require a diagram for an answer \\
\hline- & Difficulty of mixing automatically graded and manually graded questions \\
\hline \multicolumn{2}{|c|}{ ADMINISTRATION } \\
\hline+ & All students have the same amount of time \\
\hline+ & Students can take the exam at different times \\
\hline+ & Students can take the exam in different places \\
\hline- & $\begin{array}{l}\text { It is more difficult to give an exam to a student not registered for the class, or one } \\
\text { who needs to take the exam early }\end{array}$ \\
\hline- & Some browsers may have trouble with the exam, or with certain questions \\
\hline- & Students may fail to save their work, or accidentally exit the exam \\
\hline- & $\begin{array}{l}\text { Students in high-security environments where only verified software/Web sites are } \\
\text { allowed may not be able to access the exam }\end{array}$ \\
\hline- & Network problems may abort exam attempts \\
\hline$x$ & Time-shifting and location-shifting facilitates cheating \\
\hline$x$ & Students may use fabricated network problems as an excuse for their own lack of preparation \\
\hline \multicolumn{2}{|c|}{ GRADING } \\
\hline+ & Automatic grading may save time \\
\hline+ & Allows exams to be more frequent \& shorter \\
\hline+ & Automatic grading perceived as more objective \\
\hline+ & Immediate feedback on automatically graded questions \\
\hline+ & Students have more of an opportunity to look over graded final exams \\
\hline+ & Students can quickly see how they compare with peers \\
\hline+ & Grading a single question at a time may be more efficient \\
\hline+ & Easier for multiple graders to interact \\
\hline+ & Grades are automatically recorded \\
\hline+ & More data is available for assessment and accreditation \\
\hline- & Automatic grading may waste time \\
\hline- & Harder to give partial credit, especially on mathematical questions. \\
\hline- & Rounding may be tricky to handle \\
\hline- & If an external gradebook is used, export/import of grades may be tricky \\
\hline
\end{tabular}




\begin{tabular}{|c|c|}
\hline \multicolumn{2}{|c|}{ ACADEMIC INTEGRITY } \\
\hline+ & Can randomize questions and answers to inhibit cheating \\
\hline+ & Can use different data sets to inhibit cheating \\
\hline+ & To discourage communication, exams can be proctored \\
\hline+ & To inhibit cheating, can prevent students from going back to earlier questions \\
\hline+ & Browsers can be "locked down" to prevent communication \\
\hline- & Randomization does not work well on all systems \\
\hline$\times$ & Easier for students to save copies of all questions \\
\hline$x$ & Proctoring not possible for students who take exam at a time or place of their choosing \\
\hline$\times$ & Students find it frustrating if they cannot go back to earlier questions \\
\hline \multicolumn{2}{|c|}{ HANDWRITING VS. CODING } \\
\hline+ & Easier for students to type than write \\
\hline+ & Easier for faculty to read typing than handwriting \\
\hline- & Automatic grading of short-answer qq. is error prone and must be checked manually \\
\hline- & System may discard answers that contain arbitrary special characters \\
\hline- & Equation editors are hard for students \& instructors to use \\
\hline- & Screen layout of questions may be unreadable on some browsers \\
\hline$\times$ & Time consuming to code questions correctly \\
\hline \multicolumn{2}{|c|}{ MISCELLANEOUS } \\
\hline+ & Some students find using a computer to be less stressful \\
\hline+ & Privacy-students have less chance to see others' graded exams \\
\hline+ & Easier to reuse questions \\
\hline+ & More "environmentally friendly" \\
\hline- & Accessibility-students with ADHD or RSI may be disadvantaged \\
\hline- & Harder to get to know students' names without passing back exams \\
\hline- & Harder to scan through test at a glance \\
\hline$\times$ & Some students find using a computer to be more stressful \\
\hline$\times$ & If institution switches to new system, may be difficult to retrieve and use old questions \\
\hline \multicolumn{2}{|c|}{ OPEN-WEB } \\
\hline+ & Closer to authentic assessment \\
\hline+ & Cannot cheat by using unauthorized materials \\
\hline+ & Allows more research \& application questions \\
\hline$x$ & Hard to tell whether students understand the answer or have simply cut $\&$ pasted it \\
\hline$\times$ & Students may waste time browsing Web for an answer \\
\hline$\times$ & Easier to cheat by communicating with others \\
\hline$x$ & Locking down browsers defeats the purpose of an open-Web exam \\
\hline
\end{tabular}


are beneficial in a wide range of situations, from distance-ed classes to classes where data is being collected for accreditation (Table 3). Open-Web exams have no obvious disadvantages except academic integrity. But even this is debatable, because the ability to give students different versions of the same question can make cheating harder. Online exams have some technological disadvantages, relating to the difficulty of entering diagrams and equations (though this is being mitigated by tablet computers).

Table 3: Situations where Online (ol) and Open-Web (ow) Exams Help and Hurt

Features of classes where online exams work well

- (ol) Distance-ed classes

- (ol, ow) Classes with technologically astute students

- (ol) Classes where randomizing inputs can give each student a different problem to work

- (ol) When simulations need to be run and interpreted

- (ow) Classes where large amounts of material have to be looked up

- (ol) Classes where data needs to be collected for accreditation

- (ol) Large classes

Features where online exams do not work well

- (ol) Material where one typically needs to draw diagrams or pictures as evidence of understanding

- (ol) Material where one has to show the work on a problem, especially when the work involves symbolic equations (calculus, etc?)

\section{CONCLUSION}

Online and open-Web exams have many advantages. Students seem to prefer them, and they appear to allow students to better demonstrate what they know. The strength of online exams is automated grading, but it comes with an overhead that may be difficult to justify in a small class. Small classes may do better with open-Web exams administered on paper. Although academic integrity is a major concern in either format, the evidence seems to indicate that it can be successfully addressed. 


\section{Author Biographies}

Ed Gehringer received the Ph.D. from Purdue University in 1979. He was a Research Associate and Lecturer at Carnegie-Mellon University between 1979 and 1984. In 1981, he held a Fulbright Postdoctoral Research Fellowship at Monash University in Melbourne, Australia. Since 1984, he has been on the faculty of North Carolina State University in Computer Science and Computer Engineering. He has taught more distance-education sections than any other faculty member in the NC State College of Engineering. He has been recognized for achievements in teaching with technology by NC State (Gertrude Cox Award honorable mention) and the Sloan Consortium (2008 Effective Practice award). He has chaired more than a dozen workshops and symposia on various areas of computing education, including the last two OOPSLA/SPLASH Educators' Symposia. His current research interests include learning analytics, text analysis for evaluating student feedback, and educational data mining.

Barry W. Peddycord III continues to work, research and write in North Carolina.

\section{References}

Boniface, D. (1985). Candidates' use of notes and textbooks during an open-book examination. Educational Research, 27(3), 201-209.

Gehringer, E. F.. (2010). Online vs. on-paper exams. ASEE 2010. Presented at the American Society for Engineering Education Annual Conference, Louisville, KY. 1010-1150.

Ioannidou, M. K. (1997). Testing and Life-Long Learning: OpenBook and Closed-Book Examination in a University Course. Studies in Educational Evaluation, 23(2), 131-39.

McDaniel, M. A., Roediger, H. L., \& McDermott, K. B. (2007). Generalizing test-enhanced learning from the laboratory to the classroom. Psychonomic Bulletin \& Review, 14(2), 200-206.

Rakes, G. C. (2008). Open book testing in online learning environments. Journal of Interactive Online Learning, 7(1), 1-9.

Wiggins, G. (1990, December). The Case for Authentic Assessment. ERIC Clearinghouse on Tests Measurement and Evaluation: ERIC ED328611.

Williams, J. B., \& Wong, A. (2007). Closed book, invigilated exams versus open book, open web exams: An empirical analysis. Proc. ASCILite 2007, 1079-1083. 